\title{
Septik Pulmoner Emboli, Olgu Sunumu
}

\author{
Septic Pulmonary Embolism, a Case Report
}

\section{Fulsen Bozkuş ${ }^{1}$, Nursel Dikmen², Nurhan Atilla ${ }^{3}$, Hüseyin Arpağ ${ }^{4}$, Hasan Kahraman ${ }^{5}$}

1 Göğüs Hastalıkları, Sütçü İmam Üniversitesi Tıp Fakültesi, Kahramanmaraş, Türkiye

2 Göğüs Hastalıkları, Necip Fazıl Şehir Hastanesi, Kahramanmaraş, Türkiye

3 Göğüs Hastalıkları, Sütçü İmam Üniversitesi Tıp Fakültesi, Kahramanmaraş, Türkiye

4 Göğüs Hastalıkları, Sütçü İmam Üniversitesi Tıp Fakültesi, Kahramanmaraş, Türkiye

5 Göğüs Hastalıkları, Sütçü İmam Üniversitesi Tıp Fakültesi, Kahramanmaraş, Türkiye

\section{ÖZET}

Septik pulmoner emboli herhangi bir enfeksiyon odağına ikincil olarak gelişen akciğer infiltrasyonları, ateş, göğüs ağrısı, öksürük gibi non spesifik akciğer semptomları ile karakterize bir hastalıktır. Konjenital kalp hastalığı, IV ilaç kullanımı, uzun süreli katater kullanımı gibi predispozan durumlarda, mikroorganizmaları içeren koagüle kanın sağ kalpten hematojen yolla akciğerlere yayılımı ile infarkt ve abse formasyonları oluşturmasıyla karakterizedir. Morbiditesi ve mortalitesi yüksek olan septik pulmoner embolinin prognozunu belirleyen en önemli faktör, erken tanı ve geniş spektrumlu antibiyoterapidir. Göğüs ağrısı, ateş, öksürük ve hemoptizi yakınması ile kliniğimize başvuran olgunun akciğer görüntülemesinde bilateral kaviter lezyonları mevcuttu. Sedimentasyonu ve C-reaktif proteini yüksek ve primer enfeksiyon odağı tespit edilemeyen olguda, tekrar alınan anamnezde yaklaşık 2 hafta önce diş absesi nedeni ile diş çektirme öyküsü olduğu belirlendi. Nonspesifik antibiyoterapi ile hızı iyleşme gözlenen ve septik pulmoner emboli tanısı alan olguyu literatür eşliğinde paylaştık.

Anahtar Kelimeler: Septik pulmoner emboli, diş çekimi, kavite.

\section{ABSTRACT}

Septic pulmonary embolism is a condition characterized by nonspecific symptoms such as fever, chest pain, cough and pulmonary infiltrates that developing secondarily to any infectious source. It is a phenomenon which has predisposing factors such as congenital heart disease, iv drug usage, long-term catheterization. It is characterized with abscess and infarct formation in lungs secondarily to hematogenous spread of coagulated blood containing microorganisms from right heart to the lungs. Early diagnosis and broad-spectrum antibiotics are the main factors determining the prognosis of septic pulmonary embolism which has high morbidity and mortality.

In our case, patient admitted to our clinic with chest pain, cough, fever and haemoptysis. It has bilateral cavitary lesions in lung scanning. However, it has high sedimentation and C-reactive protein level, primary infection could not detected. In more detailed anamnesis of patient, there was a history of dental abscess treatment. It was diagnosed with septic pulmonary embolism and treated with non-specific antibiotherapy and healed fastly. The aim of this case report is to provide an overview of septic pulmonary embolism, with existing literature.

Keywords: Septic pulmonary embolism, tooth extraction, cavitary.
Corresponding Author: Fulsen Bozkuş

Address: Sütçü İmam Üniversitesi, Tıp Fakültesi, Kahramanmaraş E-mail: fulsenbatmaz@gmail.com
Başvuru Tarihi/Received: 24-12-2015

Kabul Tarihi/Accepted: 21-02-2016 


\section{Giriş̧}

Septik pulmoner emboli (SPE), septik flebitteki enfekte fibrin trombüsten, akciğere embolizasyon olması sonucu pulmoner damarlarda tıkanıklık, pulmoner enfarkt ve pulmoner enfeksiyon gelişmesine bağı bir klinik tablodur. Enfektif endokardit, tonsiller, juguler, dental, pelvik bölge, enfekte santral venöz kateter gibi bir enfeksiyon odağından hareket eden fibrin içine yerleşmiş mikroorganizmaları içeren bir trombüs pulmoner arterlere yerleşmekte ve bilateral akciğer parankiminde genellikle periferik ve damar komşuluğunda yerleşen, multipl ve bilateral nodüler, kaviter veya kama şeklinde infiltrasyonlara yol açmaktadır [1,2]. SPE'li hastalar ateş, dispne, öksürük, plöretik göğüs ağrısı ve hemoptizi şikayeti ile başvurabilir. Başlangıçtaki klinik ve radyolojik özellikler genellikle nonspesifik olduğu için tanısı sıklıkla zordur. İmmün yetmezlik, intravenöz uyuşturucu madde kullanımı, prostetik kalp kapağı, pacemaker enfeksiyonu, fokal ekstra pulmoner infeksiyon varlığı hastalığın gelişmesinde predispozan faktörlerdendir. SPE prognozunu belirleyen en önemli faktör, erken tanı ile birlikte uygun geniş spektrumlu antibiyotik tedavisinin başlanmasıdır [3].

\section{OLGU SUNUMU}

Otuzdört yaşında bayan hasta bir haftadır olan göğüs ağrısı, öksürük, ateş ve balgamla kan gelmesi şikayeti ile polikliniğimize başvurdu. Fizik muayenesinde genel durum iyi, bilinci açık, koopere, oryante idi. Aksiller ateşi 39으, TA: 120/80 mmHg, nabız hızı 110/dk olup periferik oksijen saturasyonu \%93 idi. Solunum sistemi muayenesinde her iki akciğer bazallerde inspiratuar ralleri mevcuttu. Diğer sistem muayenelerinde özellik saptanmadı. Laboratuvar değerlerinde; lökosit: 7.430/uL, sedimantasyon: 91 mm/h, CRP: $118 \mathrm{mg} / \mathrm{L}, \mathrm{Hb}: 10.3 \mathrm{gr} /$ dL, Htc: \%31.5, üre: $12 \mathrm{mg} / \mathrm{dl}$, kreatinin: $0.6 \mathrm{mg} /$ dl, ALT: $21 \mathrm{U} / \mathrm{L}, \mathrm{AST}: 19 \mathrm{U} / \mathrm{L} \mathrm{Na:} 140 \mathrm{mEq} / \mathrm{L}, \mathrm{K}: 4.2$ $\mathrm{mEq} / \mathrm{L}, \mathrm{Ca}: 8.9 \mathrm{mEq} / \mathrm{dl}, \mathrm{Cl}: 105 \mathrm{mEq} / \mathrm{dl}$ olup biyokimyasal parametrelerinde patolojik özellik yoktu. Koagülometrisi ve tam idrar tahlili normaldi.

Çekilen arka-ön akciğer grafisinde, bilateral kaviter lezyonlar izlendi (Şekil 1). Bilgisayarlı toraks tomografisinde (BT) bilateral periferik yerleşimli kaviter lezyonlar gözlendi (Şekil 2). Hastaya ampirik olarak intravenöz seftriakson ve oral metranidazol başlandı. Olgu tüberküloz yönünden değerlendirildiğinde gönderilen 3 balgamın ehrlich-ziehl-neelsen boyama yöntemi ile boyandığında sonucun negatif olduğu görüldü. Enfektif endokarditi ekarte etmek için hastaya ekokardiografik değerlendirme yapıldı, sonucu normal olarak değerlendirildi ve kapaklarda vejetasyona rastlanmadı. SPE ön tanısı olan hastanın anamnez sorgulaması ayrıntılı yapıldığında yaklaşık 15 gün önce diş absesi nedeni ile diş hekimine gittiği ve diş çekimi yaptırdığı öğrenildi. SPE'de sıklıkla staphiloccus aureus etken olması sebebiyle hastada intravenöz vankomisin ve ciprofloksasin tedavisine geçildi. Hastanın kan kültürlerinde üreme olmadı. Bir haftalık tedavi sonrası ateşi düşen, CRP ve sedimantasyon hızı değerleri normale dönen, vital bulguları stabil olarak takip edilen hastanın tedavisi 21 güne tamamlanarak taburcu edildi. Hastanın poliklinik kontrollerinde radyolojik olarakta belirgin düzelme gözlendi (Şekil3-4).

\section{TARTIŞMA}

SPE nadir görülen, semptom ve bulgularının spesifik olmaması sebebi ile tanısı zor olan bir hastalıktır. SPE'nin etyopatogenezinde IV ilaç bağımlılığı, enfektif endokardit, alkolizm, lenfoma, ağır deri enfeksiyonları, hemodializ uygulanan olgulardaki $\mathrm{A}-\mathrm{V}$ şantlar, osteomyelit, immün yetmezlikler, mastoidit, toksik şok sendromu, Lemierre sendromu, karaciğer apsesi, periodontal hastalıkların rol oynadığı gösterilmiştir [4]. Enfektif endokarditteki tipik lezyon platelet, fibrin, mikroorganizma ve inflamatuar hücrelerden oluşan vejetasyonlardır. Önceden var olan kalp hastalığı, bakteriyemi oluşumu ve enfektif endokarditin ortaya çıkışı arasındaki bağlantı çok eski yıllardan beri bilinmektedir [5]. Bakteriyemiler yalnızca diş çekimi, tonsillektomi ve bronkoskopi gibi büyük girişimlerden sonra değil, diş fırçalama esnasında bile oluşabilir ve SPE' ye yol açabilir [6]. Bizim olgumuzda, septik emboli nedeni olarak diş absesi sebebi ile diş çekim öyküsü saptandı fakat yapılan ekokardiyografik değerlendirmesinde kapaklarda vejetesyon olmadığı için enfektif endokardit ekarte edildi. 

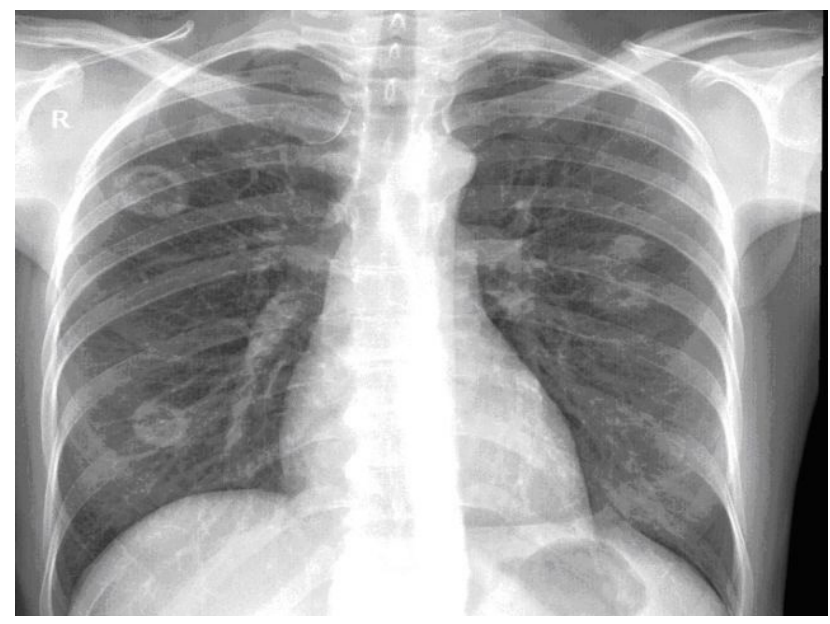

Şekil 1

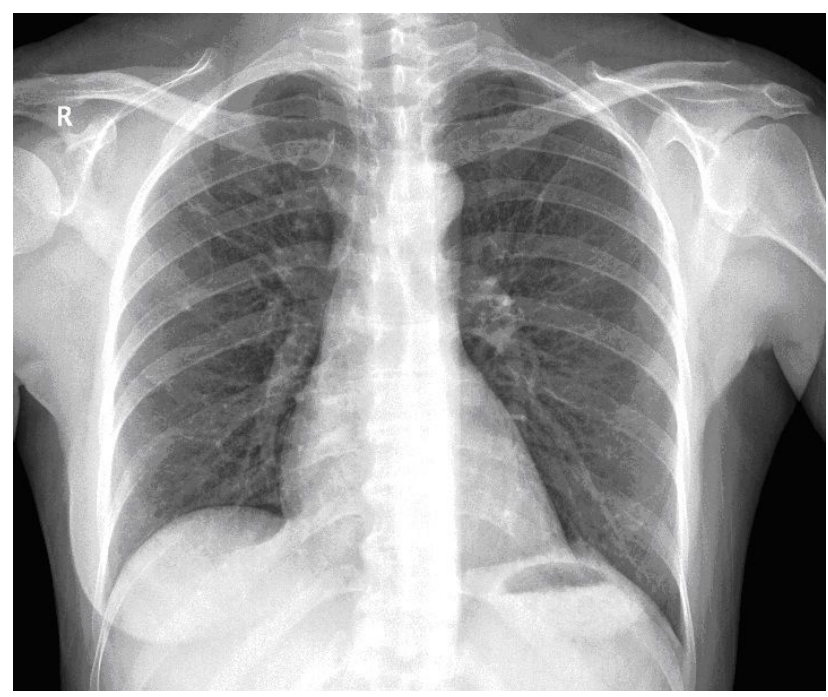

Şekil 3

SPE klinik özelliklerini belirlemek için yapılan bir çalışmada olgular yeniden incelenmiş ve SPE'nin en sık görülen klinik bulgularının sırası ile ateş, nefes darlığı, göğüs ağrısı ve öksürük olduğu tespit edilmiş, sonuç olarakta SPE'nin kendine özel klinik bulguları olmayan nadir bir hastalık olduğu bildirilmiştir [7]. Bizim olgumuzda da başvuru şikayeti olarak öksürük, göğüs ağrısı, ateş ve hemoptizi bulunuyordu. Göğüs ağrısı ve ateş her zaman SPE'ye spesifik bulgu olmamakla beraber olgumuzdaki spesifik radyolojik bulgular ve sekonder enfeksiyon kaynağı olarak periodontal abse olması bu olguda bize SPE tanısını koydurmuştur.

SPE'nin hem ayırıcı tanısında hem de tanısında radyoloji oldukça önemlidir. Arka-ön akciğer grafisinde periferik parankimal nodüller ile ince-or-

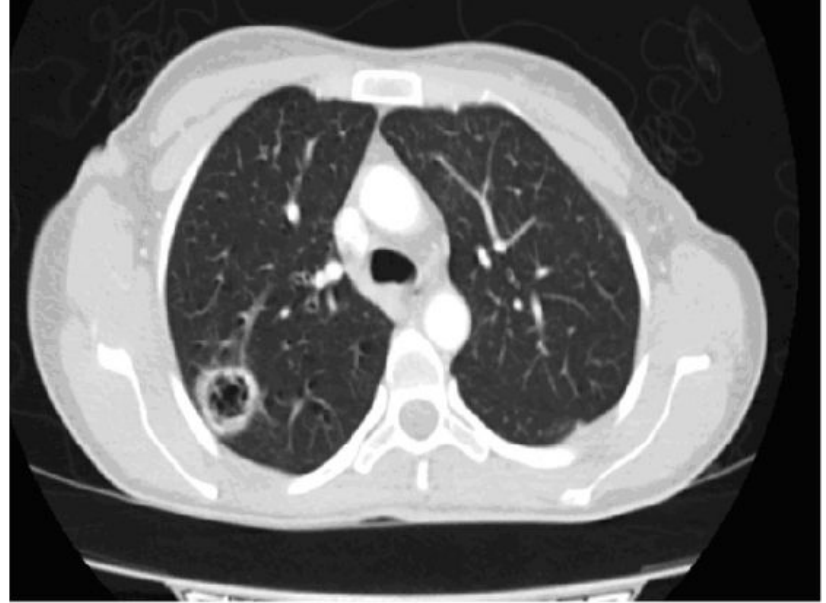

Şekil 2

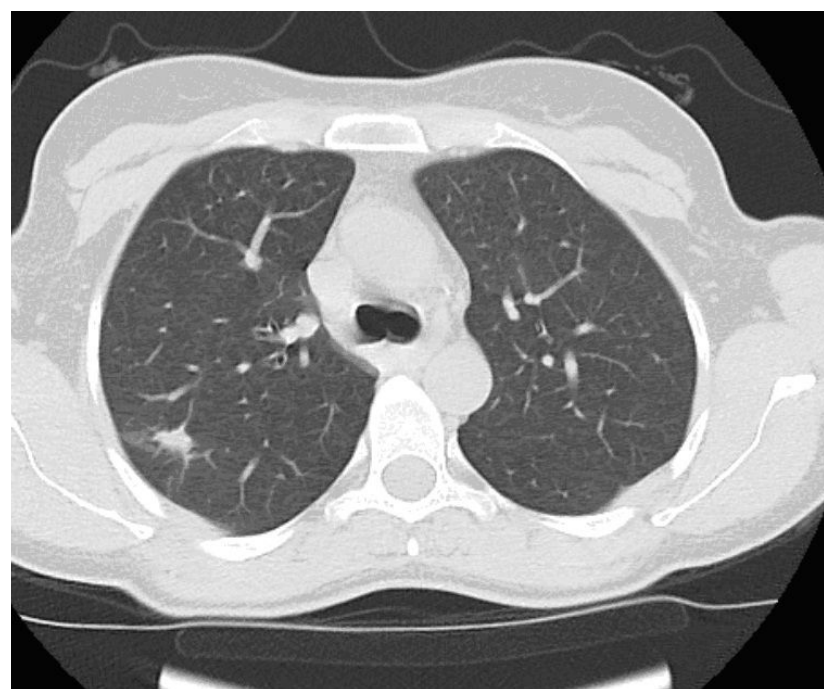

Şekil 4

ta kalınlıkta irregüler duvara sahip kavitasyonlar tipik olmakla beraber, SPE tanısını koymada tomografi akciğer grafisinden daha üstündür. Kavitasyonlar, enfarktın enfeksiyöz kökenli olduğunun önemli bir bulgusudur. Ayrıca toraks BT hem abse formasyonlarının plevral boşluğa yayılımın gösterilmesi gibi komplikasyonların görüntülenmesinde faydalı hem de hastalık progresyonunun takibinde diğer görüntüleme yöntemlerine göre üstündür [8]. Olgumuzda her iki akciğer parankiminde santralinde kavitasyon görülen multipl hiperdens nodüler lezyonlar ve sol akciğerde santralinde kavitasyon olmayan nodüler dansite mevcuttu.

SPE etyolojisinde sıklıkla staphylococcus aureus etkendir [3]. Stafilokokların yanısıra viridan streptokoklar ve klebsiella pnomonia da sebep 
olabilir [9]. Olgumuzun kan kültürlerinde herhangi bir üreme olmamış ve enfeksiyon kaynağı olarak belirlenen diş absesine bağlı ampirik olarak başlanılan vankomisin ve ciprofloksasin tedavisine yanıt alınmıştır. Dental enfeksiyonlara sekonder gelişen SPE ile ilgili yapılan bir araştırmada toplam 9 olguya ulaşmışlar, bunlardan 5 'inde periapikal periodontitis 3 'ünde gingival apse tespit etmişlerdir. Aynı çalışmada 9 olgunun 6'sı imipenem/silastatin, vankomisin, klindamisin, siprofloksasin gibi paranteral antibiyotiklerle tedavi edilirken 2 olgu amoksisilin, klaritromisin ve oral siprofloksasin gibi oral antibiyotikler ile tedavi edilmiştir. Bu çalışmanın sonucuna göre SPE'nin dental enfeksiyonlara sekonder olarak gelişebileceğini, bu olgularda genelde kan kültürlerinde üremenin olmadığını ve en yaygın semptomun göğüs ağrısı ve dental semptomlar olduğunu bildirmişlerdir [10]. Olgumuzda da literatürle uyumlu olarak, kan kültüründe üreme olmamış ve ilk başvuru semptomlarından biri gögüs ağrısı olmuştur.
SPE ayırıcı tanısında metastaz, tüberküloz, mantar ve gram (-) enfeksiyonlar, paraziter enfeksiyonlar (kist hidatik), romatoid artrit, wegener granulomatozisi gibi romatolojik patolojiler akılda tutulmalıdır. Bu olguda semptom ve bulguların uyumlu olması, hastada predispozan faktör olarak dental abse hikayesi olması, toraks tomografisinde SPE ile uyumlu bulguların görülmesi nedeniyle septik pulmoner emboli düşünüldü.

Sonuç olarak; SPE nadir görülen klinik bir durumdur. Tedavi yönetiminde erken tanı, uygun antimikrobiyal tedavinin hemen başlanması, ekstrapulmoner enfeksiyon kaynağının da tedavisi oldukça önemlidir. SPE özellikle risk faktörlerini taşıyan hastalarda her zaman akılda tutulması gereken, tanı ve tedavisi zor olan ve nadir görülen bir klinik tablo olması nedeniyle bu olguyu sunmayı uygun bulduk.

\section{KAYNAKLAR}

1. Morris TA, Fedullo PF. Pulmonary Thromboembolism. In Mason RJ, Murray JF, Nadel JA. Editors. Textbook of Respiratory Medicine. 5th ed. Saunders; 2010. p.1216.

2. Tanrıverdi F, Kurtoğlu G, Gül Ç, Günaydın P, Coşkun $S$, Erşen T. Intravenöz Uyuşturucu Madde Bağımlısı Hastada Gelişen Septik Pulmoner Emboli. JAEMCR 2014;5:180-2.

3. Cook RJ, Ashton RW, Aughenbaugh GL, Ryu JH. Septic pulmonary embolism: presenting features and clinical course of 14 patients. Chest 2005;128(1):162-6.

4. Pulmonary thromboembolism. In: Murray JF, Nadel JA eds.Textbook of respiratory medicine. 3rd Edition. WB Saunders Company, 2000. p.1503-1531.

5. Berlin JA, Abrutyn E, Strom BL, Kinman JL, Levison $\mathrm{ME}$, Korzeniowski $\mathrm{OM}$ et. al. Incidence of infective endocarditis in the Delaware Valley, 1988-1990. Am J Cardiol 1995;76(12):933-6.
6. Hart GH, Foster JW, Luther MF, Kanter MC. Stroke in infective endocarditis. Stroke 1990;21(5):695-700.

7. Ye R, Zhao L, Wang C, Wu X, Yan H. Clinical characteristics of septic pulmonary embolism in adults: A systematic review. Respir Med. 2014;108(1):1-8.

8. Iwasaki Y, Nagata K, Nakanishi M, Natuhara A, Harada $\mathrm{H}$, Kubota $\mathrm{Y}$ et al. Spiral CT findings in septic pulmonary emboli. Eur J Radiol 2001;37(3):190-4.

9. Lee $\mathrm{SJ}$, Cha $\mathrm{SI}$, Kim $\mathrm{CH}$, Park JY, Jung $\mathrm{TH}$, Jeon $\mathrm{KN}$ et al. Septic pulmonary embolism in Korea: Microbiology, clinicoradiologic features, and treatment outcome. J Infect 2007;54(3): 230-4.

10. Shiota $Y$, Taniguchi A, Yuzurio S, Horita N, Hosokawa $S$, Watanabe $Y$ et al. Septic pulmonary embolism induced by dental infection. Acta Med Okayama. 2013;67(4);253-8. 